\title{
Optimization research on the site selection of fire safety for mega projects sites based on multi-objective particle swarm
}

\author{
Yong Xiang ${ }^{1} \cdot$ Wuwen $\mathrm{Cao}^{1} \cdot$ Huidan $\mathrm{Zheng}^{1} \cdot$ Yangyang Su${ }^{1}$
}

Received: 11 May 2020 / Revised: 20 September 2020 / Accepted: 28 October 2020 / Published online: 23 November 2020

(c) The Author(s) 2020

\begin{abstract}
There are large fire safety hidden dangers in the construction site of mega-projects. In order to improve the ability of fire safety emergency response on site, in this paper, the number of demand points on the construction site are firstly determined, and through using risk assessment of operating conditions method, the risk is evaluated and the risk level is determined. Secondly, according to the construction site layout criteria and fire safety technical criteria, and taking the economy, distance, time and coverage of fire safety site selection as the basic factors, a multi-objective site selection optimization model for fire safety points is established. Multi-objective particle swarm optimization is used to solve the multi-objective site selection model, and a series of fire safety point site selection schemes are obtained. Finally, the analytic hierarchy process is used to select the best scheme from a series of schemes. The research ideas and conclusions of this paper provide a scientific and reasonable analysis framework and ideas for site selection of fire safety points for mega projects, which has certain applicability and practicability.
\end{abstract}

Keywords Mega projects $\cdot$ Fire safety point $\cdot$ Multi-objective particle swarm optimization $\cdot$ Site selection optimization

\section{Introduction}

According to the concept and nature of mega projects expounded by academic and theoretical circles, it can be recognized that the site management of mega projects has the characteristics of complexity and wide scope $[1,2]$. Therefore, it is more important to solve the fire safety emergency management problem in construction site. Siting selection of fire safety points in construction site for mega projects has a great practical significance for ensuring safety production of construction sites and reducing fire safety accident losses.

Yangyang $\mathrm{Su}$

syy2398075011@163.com

Yong Xiang

xiangyong@mail.xhu.edu.cn

Wuwen Cao

caowuwenliang@163.com

Huidan Zheng

zhd19940726@163.com

1 Department of Engineering Cost, School of Civil Engineering, Architecture and Environment, Xihua University, Sichuan Province, 999\# Jin Zhou Rd. Jin Niu District, 610039 Chengdu, People's Republic of China
Recent years, big data are widely recognized as being one of the most powerful drivers to promote productivity, improve efficiency, and support innovation [3].Nowadays, there are two significant tendencies, how to process the enormous amount of data, big data, and how to deal with the green issues related to sustainability and environmental concerns [4].We discuss big data meeting green challenges in the contexts of CPS) [5].This paper discusses the roles and opportunities that ICTs play in pursuing the SDGs) [6]. In recent years, multi-objective particle swarm optimization (MPSO) has become a fast-developing artificial swarm intelligence search method. Because of its fast convergence, simple operation and few parameters to be adjusted, it has a good solution advantage in optimization problems, so it has a good application prospect in many fields such as engineering construction, mechanical engineering, computer engineering and so on [7].

Foreign scholars had put forward a lot of models and methods for site selection of fire safety. They studied from different angles and adopted different methods for site selection. Murray and Wei [8] pointed out that setting coverage site selection was an important and challenging spatial optimization problem. Masood et al. [9] combined multi-objective programming theory with fire station site selection for 
the first time for carrying analysis and research, and established a multi-objective mathematical programming model for fire station site selection planning. The main factors were considered in the model, including the response time of fire station, the distance of fire station and the minimization of fire capital investment, and so on. Araz et al. [10] proposed a multi-objective site selection model for emergency service based on Euclidean distance. The model mainly considers three factors: fire station coverage, response time and response distance. Tzeng and Chen [11] proposed a fuzzy multi-objective fire station site selection method to help airports determine the optimal site selection and numbers of fire stations, and assist relevant authorities in planning and selecting fire station site selection. Cath Reynolds and Jim Pedroza [12] analyzed the load of fire station and fire vehicle from the perspective of fire power evaluation; Masood A Badri et al. [13] made a series of analysis on fire station layout from the perspective of multi-objective mathematical model. Kanoun and other scholars [14] used a target program to design the site selection of fire stations in Tunisia.

Many domestic scholars began to use various methods to plan the site selection of fire stations. For example, $\mathrm{Xu}$ Zhisheng et al. [15] studied and analyzed the factors affecting site selection of fire stations, and put forward an evaluation index system for the layout of regional fire stations. Based on the theory of multi-objective planning, a multi-objective planning model of fire stations considering time, economy, society and environment was established. WEI Lai et al. [16] studied and analyzed the basic principles of fire station planning. Combining GIS with AHP, based on the theory of multi-objective programming, a fire station site selection planning model was proposed. Zhang Yuanxue et al. [17] combined the theory of system safety engineering with relevant mathematical theories and methods, and according to the basic theory of regional fire risk assessment, the fire risk assessment of dangerous sources in the region is carried out. Wu Lizhi [18] gave the cost-benefit principle of fire station layout from the determination of fire responsibility area and cost-benefit point of view; [19] according to the division of responsibility areas, that is, the number of fire stations has been determined, Chen Chi and Ren Aizhu used the shortest weighted distance from each protected area to each fire station to analyze the optimal layout of fire stations. Liu et al. [20] proposed a new method of optimum site selection of fire station considering multiple targets by using geographic information system (GIS) and ant colony algorithm (ANT).Yang and other scholars [21] determined the optimal site selection of fire stations and facilitied by combining the method of fuzzy multi-objective programming and genetic algorithm. In the case of analyzing the basic principles of site selection of fire station, Wei Lai et al. [22] comprehensively used GIS and AHP to objectively select and assign the factors affecting the layout of site selection of fire station, and then planed the site selection of fire station.

Most of the researches on site selection for fire safety models at home and abroad aimed at conventional projects. With the development of economy and technology and the concept of giant projects, the research of the site selection of fire safety points in construction site is relatively rare. Therefore, in this paper, aiming at the emergency management of fire safety on site of mega-projects, considering the factors of economy, distance between fire safety point and demand point, time factor and coverage rate, the site selection model of fire safety point of giant project construction site is established, and the layout of the selected scheme is optimized.

\section{Basic analysis thought on fire safety site selection}

Basic analysis thought on fire safety site selection is:

1. Layout construction site: The general plan of the construction site of the construction project includes the proposed buildings, temporary houses and temporary facilities. Its layout must follow the relevant laws and regulations of (Code for Design of Construction Organization) and (Technical Code for Fire Safety in Construction Site). Specific norms are as follows:

- The layout of temporary houses and facilities shall meet the requirements of fire

- Prevention, fire fighting and safe evacuation of personnel on site.

- The fire protection spacing between the inflammable and explosive dangerous

- Goods warehouse and the construction in process shall not be less than $15 \mathrm{~m}$, the fire prevention distance between the combustible material yard and its processing yard, fixed fire operation yard and the construction in process shall not be less than $10 \mathrm{~m}$, and the fire prevention distance of other temporary housing, temporary facilities and construction in process shall be not less than $6 \mathrm{~m}$ [23].

- The layout is scientific and reasonable, and the second handling is reduced.

- Division of construction area and temporary occupancy of site shall meet the requirements of overall construction deployment and construction process, reduce mutual interference, and make full use of existing buildings and facilities to serve the project construction, so as to reduce the construction cost of temporary facilities [24]. 
2. Determine demand points: According to the mega project site, the number of buildings and temporary facilities to be built are determined as the number of demand points. The Cartesian coordinate system is established and the coordinates of each requirement point are given. In order to conveniently calculate and select the center position of each demand point as its coordinate point, rectangular coordinate system is established with the lower left corner of the map as the origin of the coordinate.

3. Determine alternative points: In this paper, LEC evaluation method is used to evaluate the fire safety risk level of demand points, and the requirement point with risk level 1 is identified as fire safety alternative point.

4. Determine the number of fire safety points: according to construction standard for fire safety point of the construction site, it estimated the cost of fire safety points. Based on the data of similar historical projects in Sichuan Province, the total annual cost of accident losses in the target area is calculated, and the number of fire safety points is calculated by using the formula.

5. Determine site selection of fire safety point: Firstly, the setting of fire safety points shall comply with the following regulations:

- Temporary fire safety points shall be set up in the decoration stage of construction in process.

- Temporary fire safety points shall be located on the long side of temporary premises arranged in groups and on the long side of construction in process.

- The width of temporary fire safety point shall meet the normal operation requirements of fire fighting equipment, and shall not be less than $6 \mathrm{~m}$. The net distance between temporary fire safety point and scaffolding outside the construction in process shall not be less than $2 \mathrm{~m}$, and shall not exceed $6 \mathrm{~m}$.

It shall be ensured that the layout of fire safety points conforms to site layout and fire safety technical specifications. The influence factors of economy, time, distance and coverage of fire safety points shall be comprehensively considered, the influencing factors are transformed into known parameters or constraints, and the site selection model of fire safety points for mega project sites is established. Using multi-objective particle swarm optimization, a series of fire safety point site selection schemes are obtained.

6. Selecting the best site selection scheme: Analytic Hierarchy Process (AHP) is used to analyze and sort out the factors such as economy, time, distance and coverage rate of each scheme, so as to determine the best site selection scheme.

\section{Determination of safety risk grade based on lec evaluation method}

According to the LEC principle [25], the possibility of fire safety accidents is recorded as $L$, the frequency of workers exposed to demand points as $E$, the consequences of fire safety accidents as $C$, and the danger of demand points as $D$. Using the product of three factors related to demand point risk, that is, $D=L \times E \times C$, so the fire safety risk coefficient of the site can be evaluated quantitatively. The bigger the $D$ value, the bigger the risk of this demand point will be.

Possibility of fire safety accidents $(L)$ : The probability of fire safety accident is related to its actual occurrence probability. The probability of absolute impossibility is 0 ; the probability of inevitable occurrence is 1 . Potential fire safety incidents must exist when examining the danger of demand points, and then the score of "minimal accident probability" is 0.1 , while the score of "Inevitable Accident" is 10 ; the median value between the two is determined according to the size of the possibility.

Frequency of workers exposed to demand points $(E)$ : The more times workers are exposed to dangerous working conditions and the longer they are exposed to dangerous working conditions, the more likely they will be injured. To this end, K.J. Graham and G.F. Ginny set a 10-point exposure frequency score for consecutive exposure to potentially hazardous environments; occasionally, the exposure frequency score was 1 . Taking 10 and 1 as reference points, they are classified according to the exposure conditions in potentially dangerous operating conditions, and the intermediate values are determined accordingly. When LEC evaluation is used for risk assessment, it has subjective consciousness to a certain extent. Therefore, in order to avoid excessive subjective interference, this paper invites university and enterprise executives to use LEC evaluation method to evaluate fire safety points.

Possible consequences of fire safety accidents once they occur $(C)$ : Personal injuries or material losses caused by accidents or dangerous events vary widely. For example, work-related accidents range from minor injuries to death. The score of minor injuries requiring ambulance is set at 1 , the possible outcome of multiple deaths is set at 100 , and other situations range from 1 to 100 .

After calculating D value, the risk level is classified according to the risk, which is generally divided into five risk levels of $1-5$. The risk score is more than 320 , which indicates that the demand point is extremely prone to fire safety accidents, and it should be considered within the coverage of fire safety points. The possibility of fire accidents, the frequency of exposure to demand points and the consequences of accidents are summarized intuitively, and 
the risk level of demand points is determined by referring to the safety risk assessment parameter table.

\section{Construction and solution of fire safety site selection}

\subsection{Construction of fire safety site selection model}

Based on the multi-objective optimization method, the economy, time, distance and coverage rate, affecting factors of fire safety points are comprehensively considered, and the influencing factors are transformed into known parameters or constraints, and the site selection model of fire safety points in construction sites of mega projects is established. Because of the complex and contradictory factors, the model established in the theory of multi-objective programming can deal with the conflicts among the factors flexibly and reflect the essential requirements of the layout of fire safety points.

\section{Economic factors}

When site selection of fire safety points is carried out at construction sites of mega projects, there will be incompatible goals. Among them, there is a contradiction between the minimization of construction cost, operation cost of fire safety points and the total loss cost of accidents in the target area. Construction cost, operation cost and total accident loss cost are the economic factors to be considered in the process of site selection of fire safety points. The magnitude of these factors is related to the number of fire safety points in the target area. If the number of fire safety points in the target area is small, serious casualties and economic losses will be caused by the untimely response when an accident occurs. However, if the number of fire safety points is too large, the construction cost and annual operation cost will be too large, resulting in waste of fire resources; therefore, there is an optimal number of fire safety points to minimize the sum of construction costs, annual operating costs and total accident losses [26],

$\min f=\sum_{p \in P} N \times S C+\alpha \times T L C \times e^{-\sum_{p \in P} N}$

In the formula (1): If $N$ is set as fire safety point, then $N=1$, otherwise $N=0 ; f$ indicates the total cost; $S C$ indicates the sum of construction cost and annual operation cost for each fire safety point; $T L C$ indicates total annual accident loss cost for a given target area; $P=\{1,2, \ldots, m\}$ is a collection of fire safety points; $p$ is fire safety point; $m$ is the number of fire safety points required to be built; $\alpha$ is an adjustable parameter; that is, in the actual situation, according to the fitting of historical data lines, the influence value of the total number of fire safety points on the actual reduction of fire accident losses is obtained.

By setting the derivative of $f$ to zero, the formula for determining the number of fire safety points can be obtained as follows:

$N=\operatorname{int}(\ln T L C-\ln S C+\beta)$

In formula (2), int indicates rounding function; $\beta$ indicates correctable probabilistic parameters, among them $\beta=\ln \alpha$.

Through the formula (2), the optimal number of fire safety points in the target area is determined.

\section{Time factor}

In the target area, if the distance between any demand point $\mathrm{q}$ and all fire safety points is compared, the distance between $\mathrm{q}$ and $\mathrm{p}$ is the shortest, then it is concluded that demand point $q$ shall be included in the jurisdiction of fire safety point $\mathrm{p}$. The distance formula from the demand point to the fire safety point is as follows: $\min D_{p q}=\left((x-i)^{2}+(y-j)^{2}\right)^{1 / 2}, \quad(i, j)$ indicates positional coordinates of possible layout of fire safety points; $(x, y)$ indicates coordinate position of fire accident. Considering the arrival speed $S_{p q}$ of fire fighting equipment comprehensively, response time is transformed into corresponding response distance for modeling [26].

$\min T=\sum_{p \in P} \sum_{q \in Q} \frac{D_{p q} \times M}{S_{p q}}$

In the formula (3): $T$ indicates total arrival time; $D_{p q}$ indicates distance from fire safety point $p$ to demand point $q$ $; Q=\{1,2, \ldots, n\}$ indicates location set of demand points; $n$ is number of demand points; If $M=1$ it means that fire safety point $p$ provides fire protection facilities to demand point $q$. Otherwise, $M=0 ; S_{p q}$ indicates that the speed at which fire safety point $p$ reaches demand point $q$.

\section{Coverage factors}

Response coverage of fire safety points is defined as the range of protection so that fire equipment can reach within a specified period of time. That is, in a certain period of time, fire fighting equipment arrives at the demand point, which accounts for the proportion of all demand points.

$R=\frac{\sum q_{i}}{Q}$

Among, $R$ indicates response coverage of fire safety points; $q_{i}$ indicates demand point of fire fighting equipment arriving in a certain time; $Q$ indicates all demand points. 
The coverage rate of fire safety points can reflect the basic requirements of fire safety points layout. $80 \%$ response coverage rate is selected as the standard. The larger the coverage rate, the higher the safety of fire safety points layout will be.

Based on the aforementioned analysis of the influencing factors of fire safety site selection, the optimization model of fire safety site selection is constructed as follows:

$\left\{\begin{array}{l}\min f=\sum_{p \in P} N \times S C+\alpha \times T L C \times e^{-\sum_{p \in P} N} \\ \min T=\sum_{p_{i} \in P} \sum_{q_{i} \in Q} \frac{D_{p q} \times M_{p q}}{S_{p q}} \\ R=\frac{\sum q_{i}}{Q}\end{array}\right.$

constrained condition : $\quad\left\{\begin{array}{l}\forall q \in Q, \sum_{p \in P} M=1 \\ \sum_{p \in P} N=m \\ \forall q \in Q, p \in P, M \leq N \\ \forall q \in Q, p \in P, M \in\{0,1\} \\ p \in P, N \in\{0,1\}\end{array}\right.$

In the constrained condition, $\forall q \in Q$ indicates that each demand point is served by only one fire safety point; $\sum_{p \in P} N=m$ indicates that the number of fire safety points planned for construction is $m$; in the formula, $\forall q \in Q, p \in P, M<N$ indicates that demand points can only be supplied by locations set as fire safety points; $\forall q \in Q, p \in P, M \in\{0,1\}$ and $p \in P, N \in\{0,1\}$ indicate decision variables.

This model is a multi-objective site selection model. Aiming at the site selection of fire safety points, not only total cost of fire safety point construction and economic factors of accident loss valu, but also the arrival time and coverage rate of fire equipment shall be considered when fire safety accidents occur. At the same time, we shall fully consider whether the conditions of each alternative site meet the requirements of building fire safety points.
NSGA-II, SPEA, SPEA2, PAES and PESA, etc. Multiobjective PSO(MOPSO) algorithm is an evolutionary technology based on swarm intelligence that simulates social behavior. With its unique search mechanism, excellent convergence performance and convenient computer implementation, it has been widely applied in the field of engineering optimization.

Site selection of fire safety points for mega-projects is a multi-objective optimization problem. Multi-objective Particle Swarm Optimization (MOPSO) is an intelligent evolutionary computing technology [27]. First, a set of random solutions are initialized, and then Pareto optimal solutions are searched by iteration and dominance relations. Because of its fast convergence, simple operation, fewer parameters to be adjusted and easy to realize the optimization results, the algorithm is scientific and operable. In this paper, an optimization model is established for the influencing factors of site selection of fire safety points in construction sites of mega projects, and multiobjective particle swarm optimization is introduced into the field of site selection optimization to analyze the applicability of multi-objective particle swarm optimization in site selection optimization model. Finally, the reasonable site selection of fire safety points in construction sites of mega projects is realized.

1. The main operators of Multi-Objective Particle Swarm Optimization

Supposed the flight speed and position of particle $i$ in the $n$-dimensional space at time $t \quad$ i s $\quad v_{i}(t)=\left[v_{i 1}(t), v_{i 2}(t), v_{i 3}(t) \cdots \cdots v_{i n}(t)\right]^{T}$, $x_{i}(t)=\left[x_{i 1}(t), x_{i 2}(t), x_{i 3}(t) \cdots \cdots x_{i n}(t)\right]^{T}$.

In the iteration process, each particle is guided by two extreme values (individual extreme pbest and global extreme gbest) to update the speed and position of the particle according to the optimal rule. Multi-objective particle swarm optimization algorithm is updated with the following formula:

$\left\{\begin{array}{l}v_{i+1}(t+1)=\omega v_{i}(t)+c_{1} r_{1}\left(\text { pbest }_{i}(t)-x_{i}(t)\right)+c_{2} r_{2}\left(\text { gbest }_{i}(t)-x_{i}(t)\right) \\ x_{i+1}(t+1)=x_{i}(t)+v_{i+1}(t+1)\end{array}\right.$

\subsection{Model solving algorithms}

In recent years, multi-objective optimization techniques based on heuristics have been greatly developed, and research shows that this technique is more practical and efficient than classical methods. Representative multiobjective optimization algorithms mainly include NSGA, where, $C_{1}, C_{2}$ represent learning factors respectively. A large number of experiments show that when $C_{1}=C_{2}=2.0$, it has a good convergence effect [29]. $r_{1}, r_{2}$ are random number between $[0,1] ; \omega$ represents the inertia weight.

2. The basic steps of multi-objective particle swarm optimization are shown in Fig. 1: 


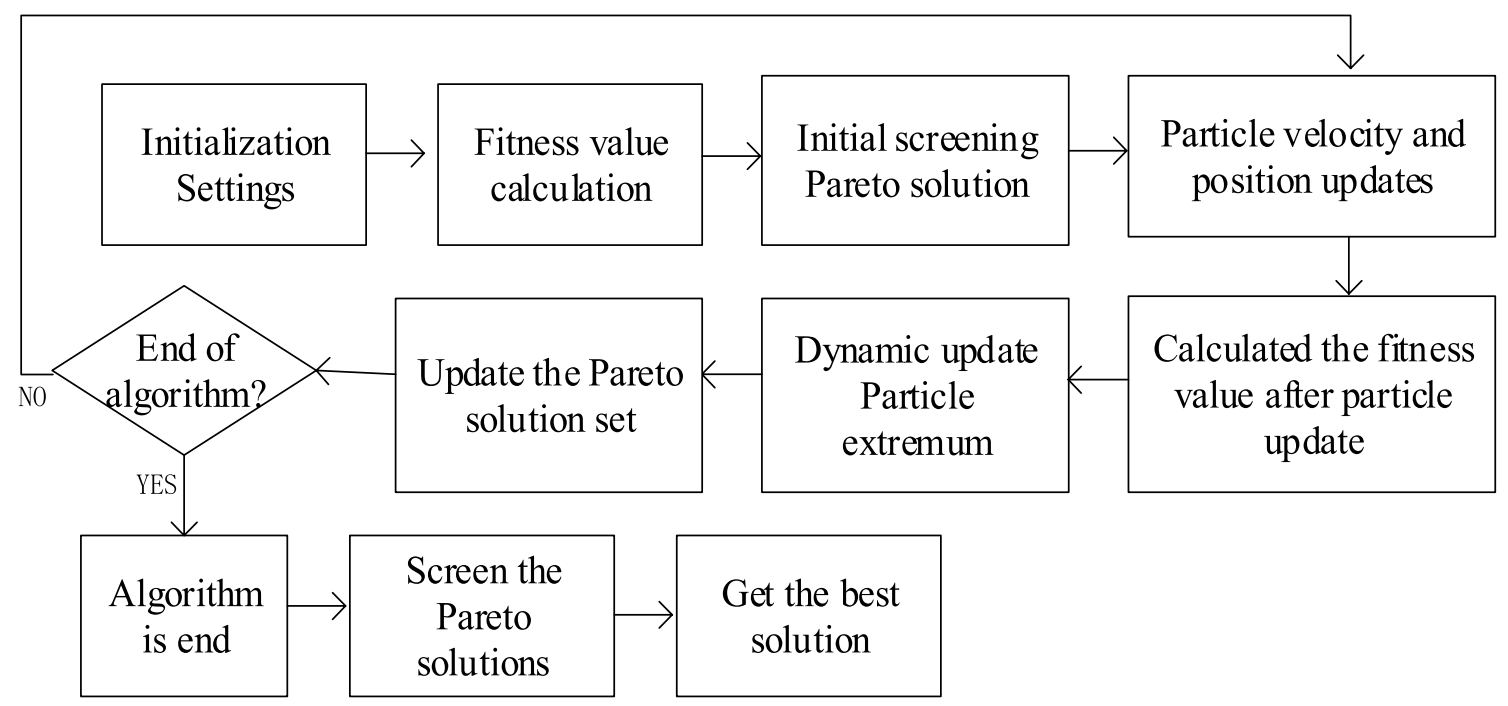

Fig. 1 Step Diagram of Multi-objective Particle Swarm Optimization

\section{Optimal selection of scheme}

\subsection{Description of analytic hierarchy process}

Analytic Hierarchy Process (AHP) refers to the decisionmaking method which decomposes the elements related to decision-making into a target level, a criterion level and a scheme level, on which qualitative and quantitative analysis can be carried out [30]. The specific flow chart is shown in Fig. 2.In the process of analytic hierarchy process (AHP), the LDA method seeks to learn low-dimensional representation from the original high-dimensional feature space through a transformation matrix. Z.L., F proposed a new criterion to maximize the weighted harmonic mean of trace ratios, which effectively avoid the domination problemwhile did not raise any difficulties in the formulation [31].

\subsection{Analytic hierarchy process site selection steps}

The basic idea of using analytic hierarchy process to select the best scheme from a series of site selection schemes is as follows: Firstly, a hierarchical structure model for selecting the best site selection scheme is established as shown in Fig. 3. Target level A is "select the best site selection scheme". Criterion level B is divided into four factors: economic factor, time factor, distance factor and coverage rate. There are schemes which have influence on the criterion level at the scheme level.

Secondly, the judgment matrix is constructed by 1-9 scale method and expert scoring method. Finally, the relative theoretical weight of each factor is calculated, and the consistency of the results is tested.

1. Construct contrastive judgment matrix

Construct judgement matrix $A=\left[\begin{array}{ccc}a_{11} & \ldots & a_{1 j} \\ \vdots & \ddots & \vdots \\ a_{i 1} & \ldots & a_{i j}\end{array}\right]$, the 1-9 scale method is usually used to determine the value of $a_{i j}$ [32].

2. Calculate the maximum eigenvalue of judgment matrix by sum method.

- The judgement matrix $\mathrm{A}$ is normalized by column: $b_{i j}=a_{i j} / \sum a_{i j}$;

- The normalized matrix is summed by row: $c_{i}=\sum b_{i j}(i=1,2,3 \cdots n)$;

- $c_{i}$ isnormalized: Weight is obtained $W^{(2)}=\left(\omega_{1}^{(2)}, \cdots, \omega_{i}^{(2)}\right)$, among $\omega_{i}^{(2)}=c_{i} / \sum c_{i} \quad(8)$;

- Find the maximum eigenvalue corresponding to weight $W^{(2)}: \lambda_{\max }=\frac{1}{n} \sum_{i}\left(\frac{\left(A W^{(2)}\right)_{i}}{\omega_{\mathrm{i}}^{(2)}}\right)$

3. Conduct consistency testing

- Calculate and measure the index $C I$ of judging the degree of inconsistency of

matrix $A$, The formula is as follows: 
Fig. 2 Analytic Hierarchy Process
Set goal

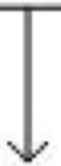

Determine the influencing factors

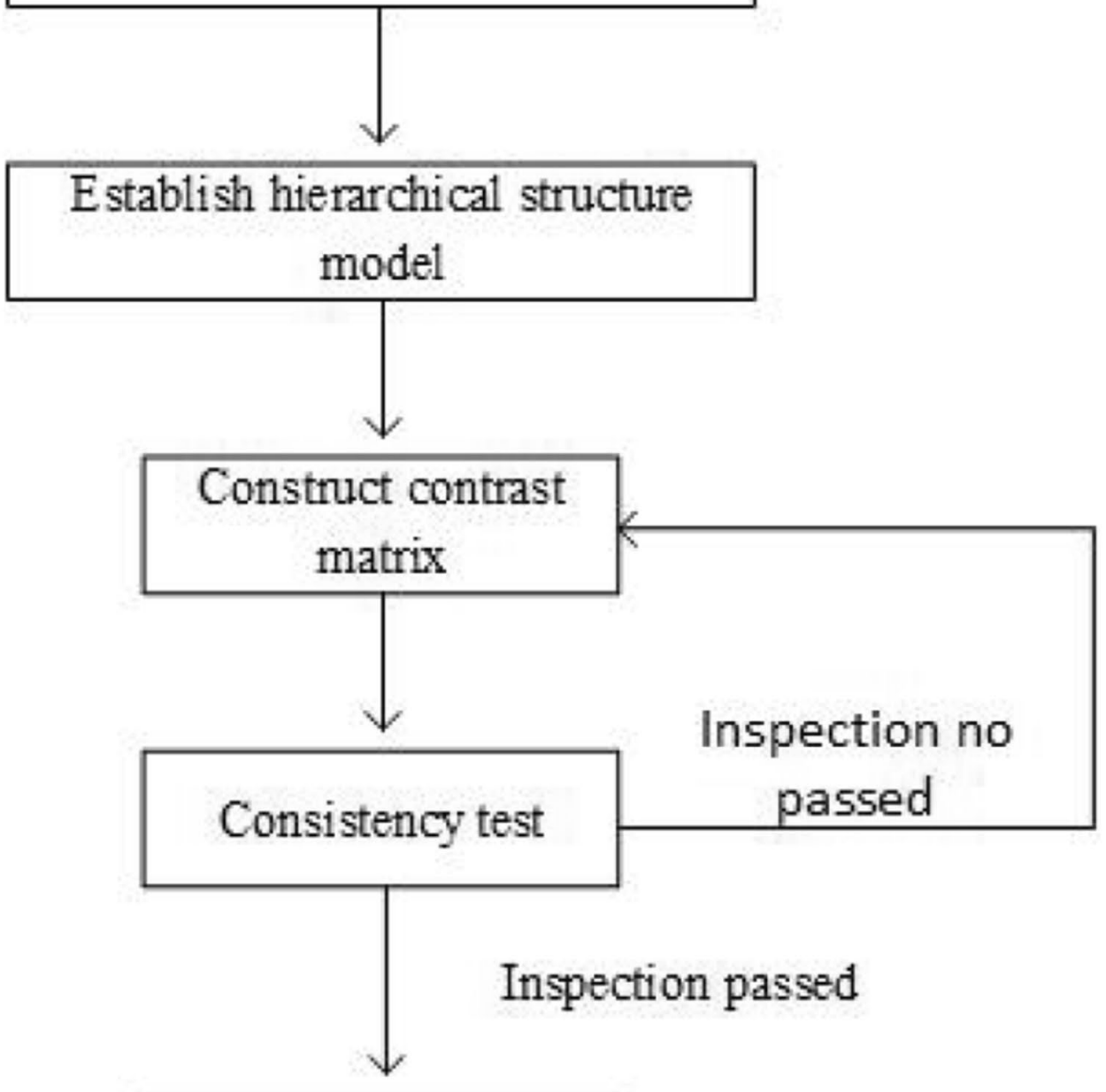

Generate the optimal solution 
Fig. 3 Hierarchical Structural Model for Screening Optimum Schemes
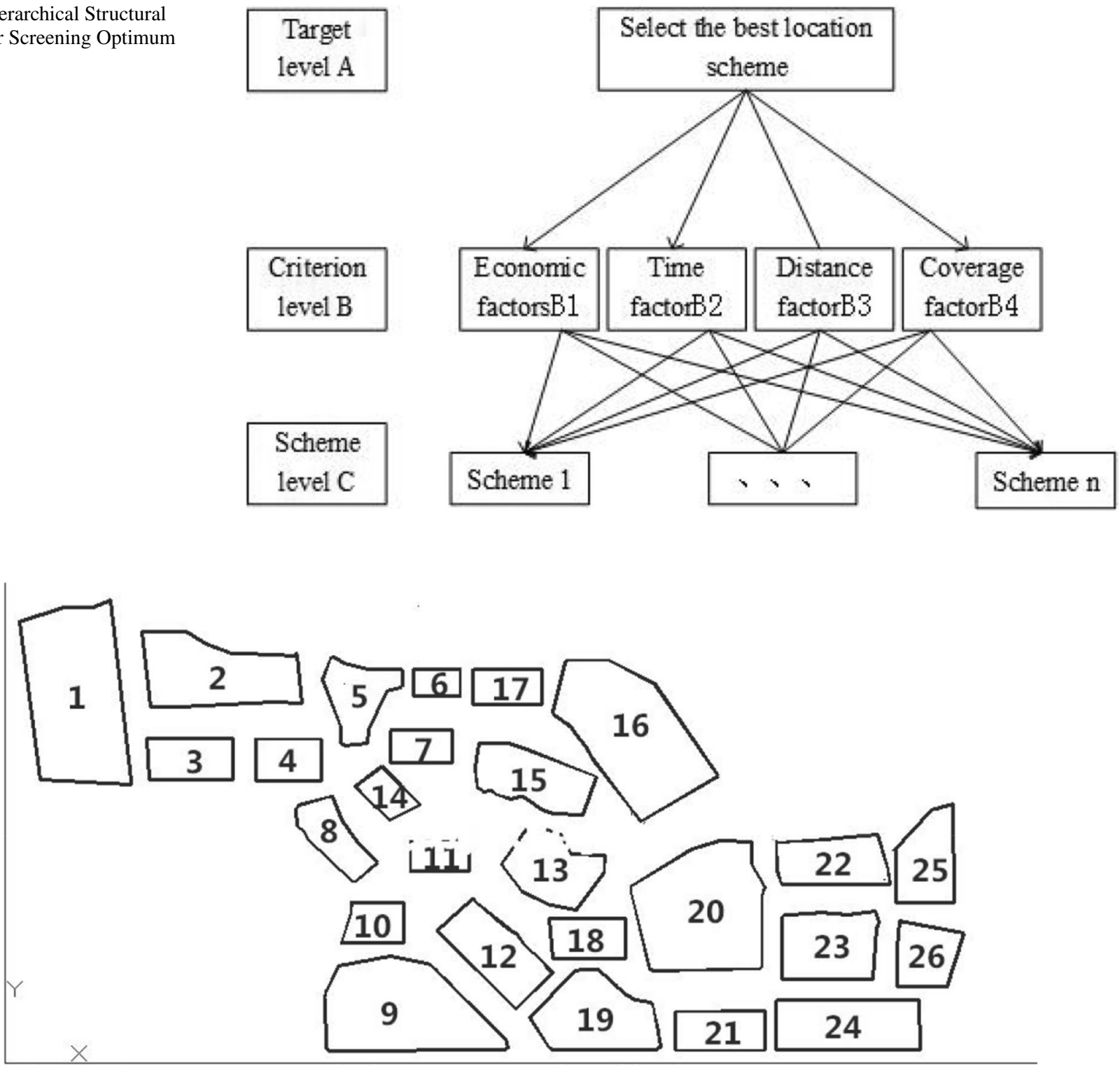

Fig. 4 Site coordinate map

$C I=\frac{\lambda_{\max }-n}{n-1}$

- Select average random consistency index $R I$ [32], and judge random consistency

Ratio $C R$ of matrix $A$

$C R=\frac{C I}{R I}$

When $C R<0.1$, judgment matrix $A$ has satisfactory consistency, or the degree of inconsistency is acceptable; otherwise, the judgement matrix $A$ is adjusted until satisfactory consistency is met [33].

Using the same method, the pairwise comparison matrix and the corresponding weights of each criterion at the scheme level to the criterion level are obtained. $W_{1}^{(3)}, W_{2}^{(3)}, \ldots W_{n}^{(3)}$.

5. Hierarchical total sorting

After obtaining the relative importance of the elements at the same level, the comprehensive importance of the elements at all levels to the target level is calculated. There are four factors at the criterion level: $b_{1}, b_{2}, b_{3}, b_{4}$, its importance to the 
target layer is matrix $W^{(2)}$; there are $n$ schemes in the scheme level;Make the weight of scheme level to criterion level as matrix: $\omega^{(3)}=\left[\begin{array}{lll}W_{1}^{(3)} & \cdots & W_{n}^{(3)}\end{array}\right]$,the overall importance of the scheme level is as follows:

$\omega=\omega^{(3)} W^{(2)}$

Finally, the scheme with higher comprehensive importance is chosen.

\section{Application case analysis}

Project overview A project is located in a high-tech Industrial Development Zone of a city in Sichuan Province. The contents of construction include: the construction of public management and public service facilities, roads and transportation facilities (including comprehensive corridors), green squares, resettlement houses and nonconstruction land management. The land area is $\mathbf{1 2 6 2 . 2 7 0}$ $\mathrm{mu}$, and the construction period of the project is five years (from March 2020). The total investment is estimated to be about 13.1 billion yuan. Because the construction site has energy sources or carriers with energy: Installation equipment (such as generators, welding machines, etc.) provides thermal energy or electric energy. building materials and materials with low ignition point (such as flammable solids, liquids, gases), materials and equipment (such as explosive flammable materials, pressure vessels, etc.) may produce huge abnormal energy. The higher the energy of fire hazard, the more serious the fire consequences will be. There are many workers in the construction site and the construction environment is complex. If a sudden fire occurs, the difficulty of evacuation will increase. Imperfect fire protection facilities will increase the difficulty of fire protection in construction sites of mega projects.

In order to facilitate calculation, the center position of each requirement point is selected as its coordinate point, and the lower left corner of the map is used as the origin of the coordinate to establish the coordinate system. The whole site coordinate map is as follows (Fig. 4).

Establish the coordinate system of project site requirement points: According to the planning map of the project, the demand points within the scope are divided, and the coordinate system is established and the coordinates of each demand point are given. The data is shown in Table 1 .

LEC evaluation method is adopted to calculate the risk points of the construction site of mega-projects and the risk level of the whole construction site is determined as shown in Table 2.

The LEC safety risk assessment model is used to calculate the demand points of construction sites for mega projects. The results show that the overall risk of construction sites is high, and 10 major hazard units are identified. They are $1(0.627,3.227), 2(1.816,3.333), 10(3.145,1.210)$, 12 (4.324,0.91), 13(4.727,1.626), $21(6.181,0.232), 22$ (7.179,1.675), 23 (7.174,1.004), 24 (7.285,0.278)and 25 (7.918,1.649). The risk is high and the consequences of accidents are wide.

\subsection{Determine the number of fire safety points}

According to the investment estimate of fire safety point construction standard, it is estimated that the construction and operation of fire safety point in construction site of this project is 3 million yuan per year. Based on the data of similar historical projects in Sichuan Province, the TLC is estimated at 14 million yuan per year; the number of demand points with high risk in construction site is 10 . Assuming that the probability of two hazards occurring simultaneously is less than $50 \%$, the revised parameter is 1.9. The above data are put into formula (2) and $N=3$ is obtained, that is, the number of fire safety points in the construction site is 3 .

\subsection{Data analysis in case algorithms}

From Sect. 6.1, 10 major hazards were found in the construction site. Three suitable addresses shall be selected to construct fire safety points. According to the index model, the site selection scheme is determined by quantitative and qualitative analysis.

The site selection and quantity of each demand point are shown in Table 3. The moving speed from alternative point to each demand point is as shown in Table 4 and the fixed investment cost (ten thousand yuan) and capacity cap $\left(\mathrm{m}^{2}\right)$ of fire safety point are as shown in Table 5.
Table 1 Coordinates of project site demand points

\begin{tabular}{lllllll}
\hline No & 1 & 2 & 3 & 4 & $\ldots$ & 26 \\
\hline $\begin{array}{l}\text { Abscissa } \\
(\mathrm{Km})\end{array}$ & 0.627 & 1.816 & 1.599 & 2.485 & $\ldots$ & 7.967 \\
$\begin{array}{l}\text { Ordinate } \\
(\mathrm{Km})\end{array}$ & 3.227 & 3.333 & 2.622 & 2.618 & $\ldots$ & 0.930 \\
\hline
\end{tabular}


Table 2 Fire Safety Risk Grade Assessment Form for Construction Sites

\begin{tabular}{|c|c|c|c|c|c|c|c|}
\hline \multirow[t]{2}{*}{ No } & \multirow[t]{2}{*}{ Risk point } & \multirow[t]{2}{*}{ Risk description } & \multicolumn{5}{|c|}{ Assessment } \\
\hline & & & $\mathrm{L}$ & $\mathrm{E}$ & $\mathrm{C}$ & $\mathrm{D}$ & Level \\
\hline 1 & Living office area & Careless use of fire, smoking & 3 & 10 & 40 & 1200 & Level I \\
\hline 2 & Placement of the housing & Electrical fire, production open fire operation, spontaneous combustion & 6 & 6 & 15 & 540 & Level I \\
\hline 3 & Woodworking shed & Open fire production, spontaneous combustion & 3 & 3 & 7 & 42 & Level IV \\
\hline 4 & Steel processing shed & Electrical fire & 3 & 3 & 15 & 135 & Level III \\
\hline 5 & High-speed Railway Mountain Park & Open fire production & 1 & 6 & 7 & 42 & Level IV \\
\hline 6 & Multistory parking area & Electrical fire, careless use of fire & 1 & 6 & 7 & 42 & Level IV \\
\hline 7 & Distribution room & Electrical fire & 1 & 2 & 7 & 14 & Level V \\
\hline 8 & District a public toilet & Open fire production & 3 & 6 & 7 & 126 & Level III \\
\hline 9 & Public plaza & Open fire production & 1 & 6 & 7 & 42 & Level IV \\
\hline 10 & Material stack site & Spontaneous combustion and smoking & 6 & 6 & 15 & 540 & Level I \\
\hline 11 & Woodworking shed & Open fire production, spontaneous combustion & 6 & 3 & 7 & 126 & Level III \\
\hline 12 & Steel processing shed & Electrical fire & 6 & 6 & 15 & 540 & Level I \\
\hline 13 & Resettlement housing & Electrical fire, production open fire operation, spontaneous combustion & 6 & 6 & 40 & 1440 & Level I \\
\hline 14 & Distribution room & Electrical fire & 3 & 2 & 7 & 42 & Level IV \\
\hline 15 & High-speed railway mountain park & Open fire production & 1 & 6 & 7 & 42 & Level IV \\
\hline 16 & Sewage Treatment Plant & Open fire production & 3 & 6 & 7 & 126 & Level III \\
\hline 17 & Parking lot & Open fire production & 3 & 6 & 7 & 126 & Level III \\
\hline 18 & Zhigu Huaxiang Park & Open fire production & 1 & 6 & 7 & 126 & Level III \\
\hline 19 & Protective green space & Spontaneous combustion & 1 & 3 & 7 & 21 & Level IV \\
\hline 20 & Protective green space & Spontaneous combustion & 1 & 3 & 7 & 21 & Level IV \\
\hline 21 & Living office area & Careless use of fire, and smoking & 3 & 10 & 40 & 1200 & Level I \\
\hline 22 & Sports venues & Open fire production, and careless use of fire & 3 & 10 & 15 & 450 & Level I \\
\hline 23 & Steel processing shed & Electrical fire & 6 & 6 & 15 & 540 & Level I \\
\hline 24 & Resettlement housing & Electrical fire, production open fire operation, spontaneous combustion & 6 & 6 & 40 & 1440 & Level I \\
\hline 25 & Material storage place & Spontaneous combustion and smoking & 10 & 6 & 7 & 420 & Level I \\
\hline 26 & Multistory parking area & Electrical fire, careless use of fire & 3 & 6 & 7 & 126 & Level III \\
\hline
\end{tabular}

Table 3 Site selection and Quantity of Each Demand Point

Table 4 Moving Speed from Alternative Point to Each Requirement Point (KM/h)

\begin{tabular}{lllllllllll}
\hline Source of risk & 1 & 2 & 3 & 4 & 5 & 6 & 7 & 8 & 9 & 10 \\
\hline Abscissa (KM) & 0.627 & 1.816 & 3.145 & 4.324 & 4.727 & 6.181 & 7.179 & 7.174 & 7.258 & 7.918 \\
Ordinate (KM) & 3.227 & 3.333 & 1.210 & 0.91 & 1.626 & 0.232 & 1.675 & 1.004 & 0.278 & 1.649 \\
Demand & 35 & 25 & 20 & 40 & 20 & 40 & 30 & 35 & 25 & 25 \\
\hline
\end{tabular}

\begin{tabular}{|c|c|c|c|c|c|c|c|c|c|c|}
\hline \multirow{2}{*}{$\begin{array}{l}\text { Alternative } \\
\text { point }\end{array}$} & \multicolumn{10}{|c|}{ Demand } \\
\hline & 1 & 2 & 3 & 4 & 5 & 6 & 7 & 8 & 9 & 10 \\
\hline 1 & 16 & 17 & 16 & 18 & 20 & 18 & 20 & 17 & 19 & 21 \\
\hline 2 & 20 & 16 & 21 & 21 & 19 & 15 & 17 & 17 & 17 & 20 \\
\hline 3 & 17 & 17 & 15 & 15 & 17 & 21 & 17 & 20 & 19 & 18 \\
\hline 4 & 18 & 21 & 20 & 17 & 18 & 21 & 18 & 15 & 16 & 18 \\
\hline 5 & 16 & 16 & 20 & 16 & 18 & 18 & 16 & 18 & 19 & 18 \\
\hline 6 & 19 & 20 & 20 & 16 & 16 & 18 & 16 & 16 & 18 & 17 \\
\hline 7 & 17 & 19 & 16 & 20 & 17 & 17 & 21 & 19 & 17 & 18 \\
\hline 8 & 19 & 21 & 17 & 19 & 16 & 21 & 21 & 19 & 19 & 18 \\
\hline 9 & 19 & 16 & 17 & 18 & 16 & 17 & 19 & 19 & 20 & 20 \\
\hline 10 & 20 & 18 & 20 & 16 & 17 & 16 & 18 & 18 & 16 & 20 \\
\hline
\end{tabular}


Table 5 Fixed Fire Safety Point Investment Costs (10,000 yuan) and Capacity Ceiling $\left(\mathrm{m}^{2}\right)$

\begin{tabular}{lllllllllll}
\hline Fire safety point & 1 & 2 & 3 & 4 & 5 & 6 & 7 & 8 & 9 & 10 \\
\hline Fixed investment(10000yuan) & 93 & 97 & 95 & 96 & 96 & 94 & 99 & 93 & 92 & 95 \\
Capacity ceiling & 140 & 150 & 130 & 130 & 130 & 150 & 160 & 140 & 150 & 130
\end{tabular}

\subsection{The solution process of examples}

In this paper, Matlab2017a software is used to realize the programming of multi-objective particle swarm optimization algorithm on the computer.

Step 1 Initialization Settings. The parameters required for the operation environment of the multi-objective particle swarm optimization algorithm are defined, including the iterations 200; acceleration constant $C_{1}=C_{2}=2$; and set the number of randomly generated particles to 100 . The position and velocity of the particle are initialized.

Step 2 Fitness value calculation. The particle position and velocity are initialized, and the particle position is substituted into the fitness function [formula (5)] to obtain the fitness value of the initial population. Each particle is defined as individually optimal.
The distribution map of initial particle fitness obtained is shown in Fig. 5.

Step 3 Initial screening non-inferior solution. The initial population is screened based on the dominant relation and the constraint condition of the project optimization objective, and the non-dominant set is constructed by the method of quicksort. Where, the dominant relation refers to: Suppose initial particles be stored in set $\mathrm{R}, x_{1}, x_{2} \in R$, where $x_{1}, x_{2}$ are any two initial particles in R. Suppose particle $x_{1}$ govern $x_{2}$. If and only if $\forall i, f_{i}\left(x_{1}\right) \leq f_{i}\left(x_{2}\right)$ exists and there is at least one $i \in\{1,2,3\}$ maing $f_{i}\left(x_{1}\right)<f_{i}\left(x_{2}\right)$, it is denoted as $x_{1} \prec x_{2}$. After initial screening of non-inferior solutions, the distribution diagram of particles is obtained, as shown in Fig. 6.

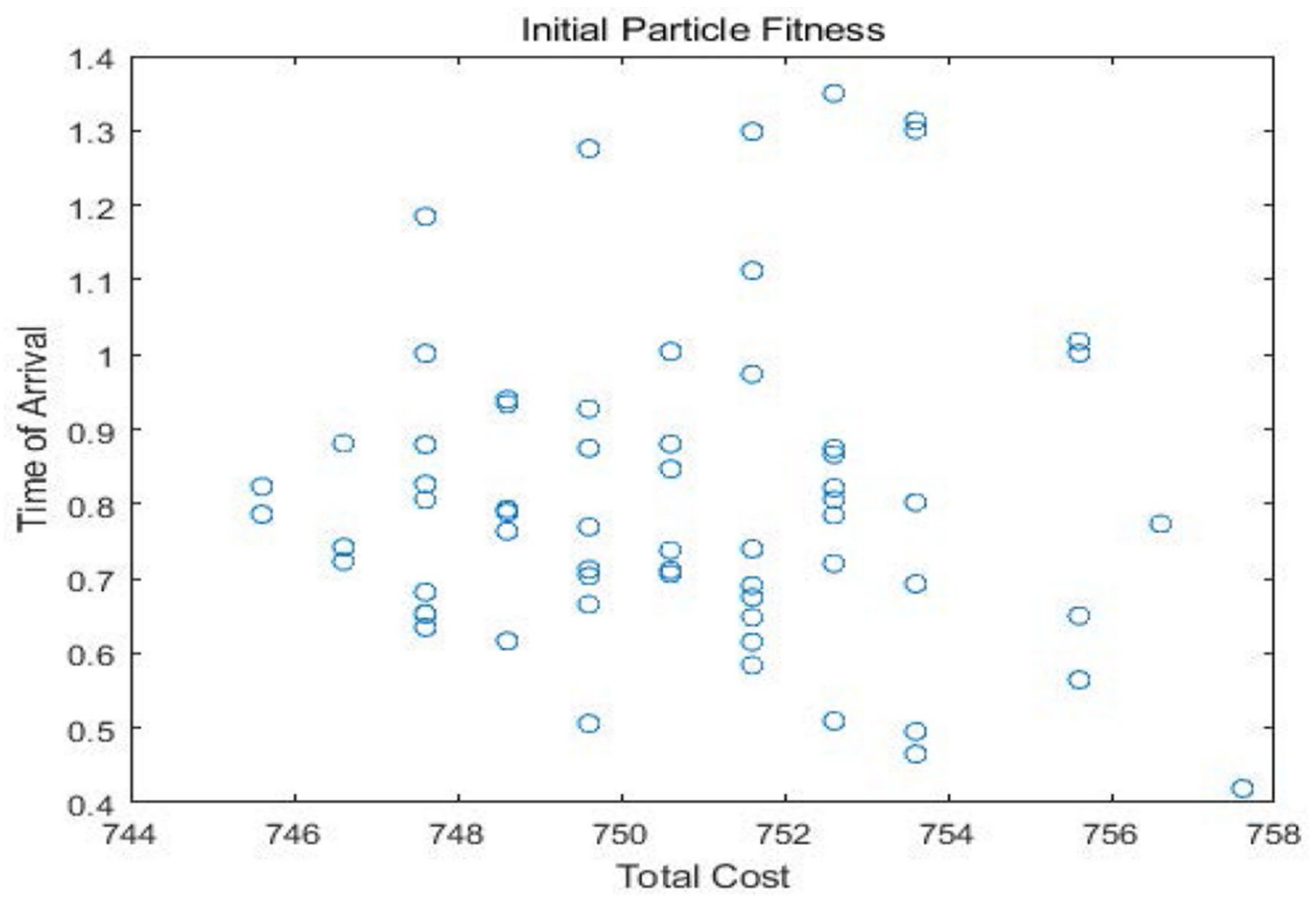

Fig. 5 Distribution Map of Initial Particle Fitness 


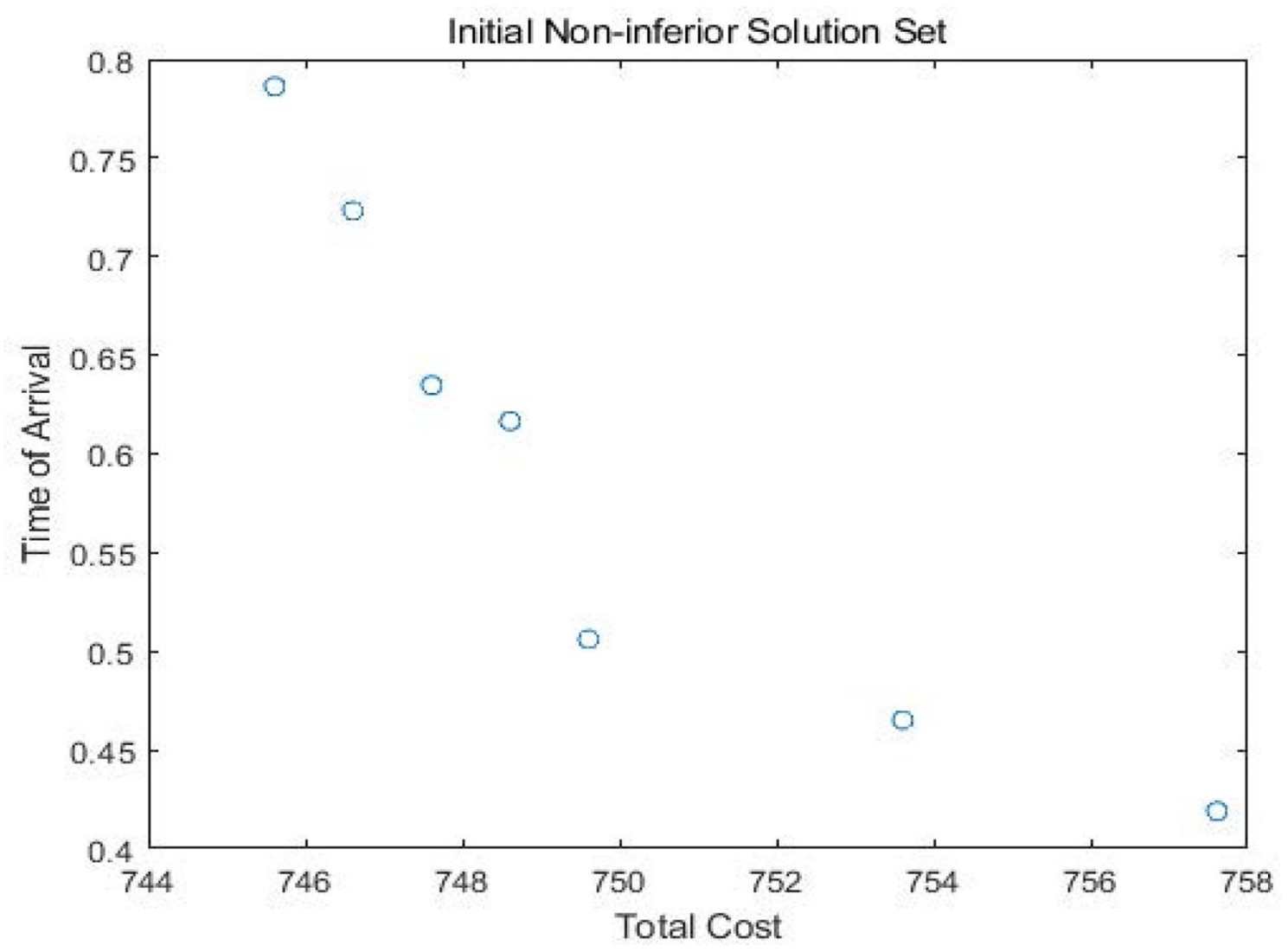

Fig. 6 Initial Non-inferior Solution Set Graph

Step 4 loop iteration. Set the number of iterations to 200. A random particle is selected from the pareto set as the optimal particle of the population.

Step 5 According to the formula of velocity and position updating [Formula (7)], the fitness values of 100 particles after velocity and position update are calculated. The population distribution after particle renewal is shown in Fig. 7.

Step 6 Best place to update particle history. The individual historical best position (xPrior) of the particle is dynamically updated based on the dominance relationship.

Step 7 Update the Pareto Set. There are two steps to update the Pareto Set. First, new Pareto Set (fljNew) are obtained by combining the Pareto Set(flj) and updated historical best particle set (xPrior). Second, according to the governing relation of Pareto Set, a new Pareto Set (fljNew) is selected. The schematic diagram is shown in Fig. 8.
Step 9 Remove duplicate particles. In order to prevent the size of the Pareto set from exceeding its carrying capacity, it is necessary to remove the repeated particles in the new Pareto set.

After 200 iterations, a set of Pareto optimal solutions is obtained. The main distribution of Pareto optimal solution is shown in Fig. 9.

From Fig. 9, we can see that the non-inferior solutions searched by the multi-objective particle swarm optimization algorithm constitute a surface, and the convergence of the algorithm is good (Table 6).

\subsection{Evaluation of fire safety point site selection scheme based on analytic hierarchy process (AHP)}

In this paper, according to the nature and characteristics of fire safety site selection, besides quantitative factors, qualitative factors shall also be considered, therefore, the singlelayer analytic hierarchy process is selected as a part of the 


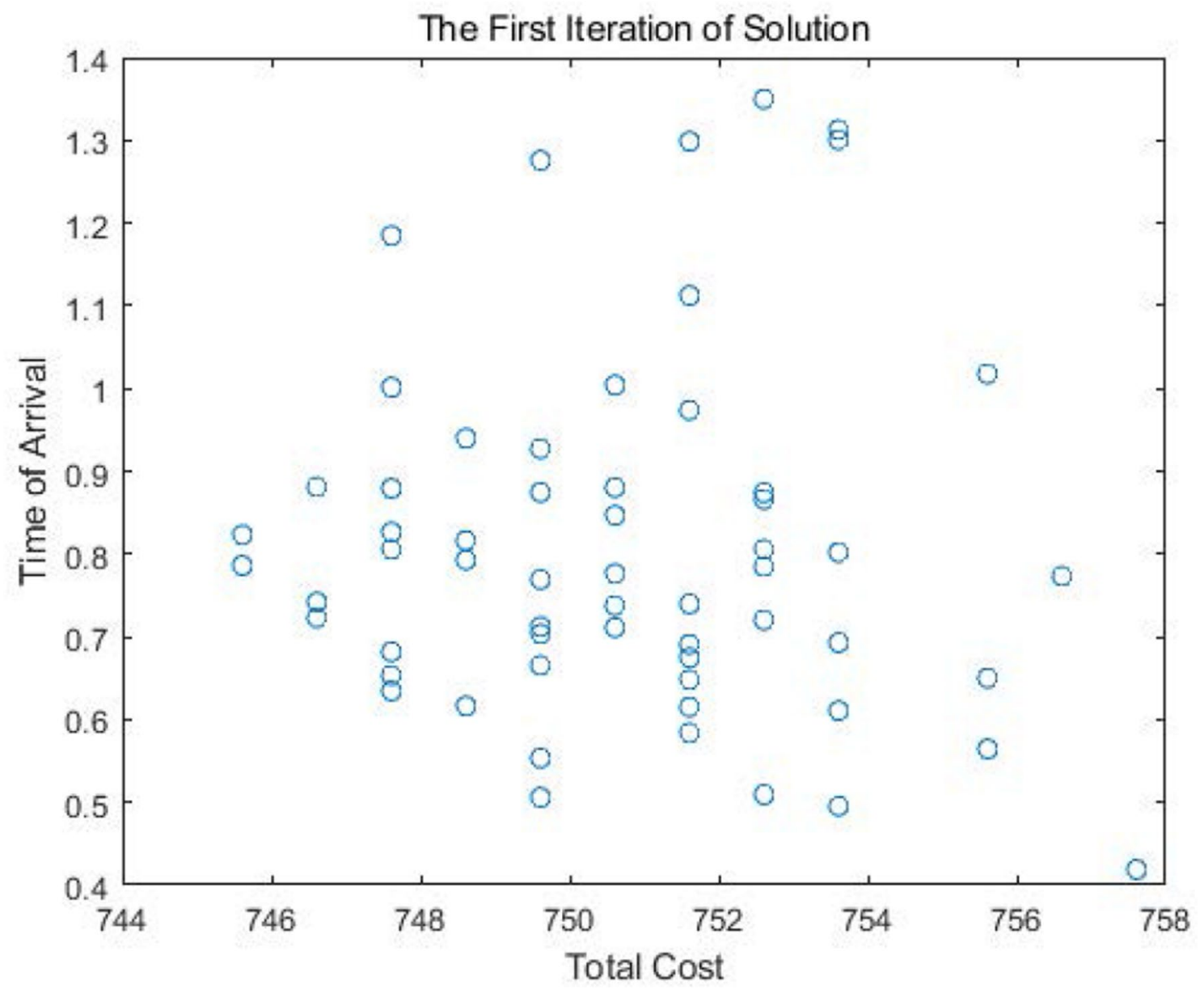

Fig. 7 The First Iteration of Solution Map

fire safety point site selection algorithm to determine the best site selection scheme. According to the characteristics of each site selection scheme, the AHP method is used to evaluate the comprehensive factors of the above seven site selection schemes, so as to determine the optimal solution of the site selection scheme.

Step 1 Compare the four factors of the criterion layer on the impact of the target layer. In the decisionmaking problem of selecting the best site selection scheme, 1-9 scale method and expert scoring method are adopted for comparing the importance of economy, time, distance and coverage in selecting the best site selection scheme, and the corresponding judgment matrix $\mathrm{A}$ is obtained as follows.
$A=\left[\begin{array}{llll}1 & \frac{1}{6} & \frac{1}{3} & \frac{1}{4} \\ 6 & 1 & 3 & 5 \\ 3 & \frac{1}{3} & 1 & 3 \\ 4 & \frac{1}{5} & \frac{1}{3} & 1\end{array}\right]$

Step 2 According to the judgment matrix, the relative weight coefficients of the elements to the criterion are calculated, and the consistency of the judgment matrix is checked.

From formula (8), the normalized eigenvectors are obtained $\omega^{(2)}=(0.067,0.55,0.237,0.146)$, that is, the weight of economy, time, distance and coverage on the target layer. From the formula (9) and (10) for carrying out obtained consistency test, the inspection is passed. 


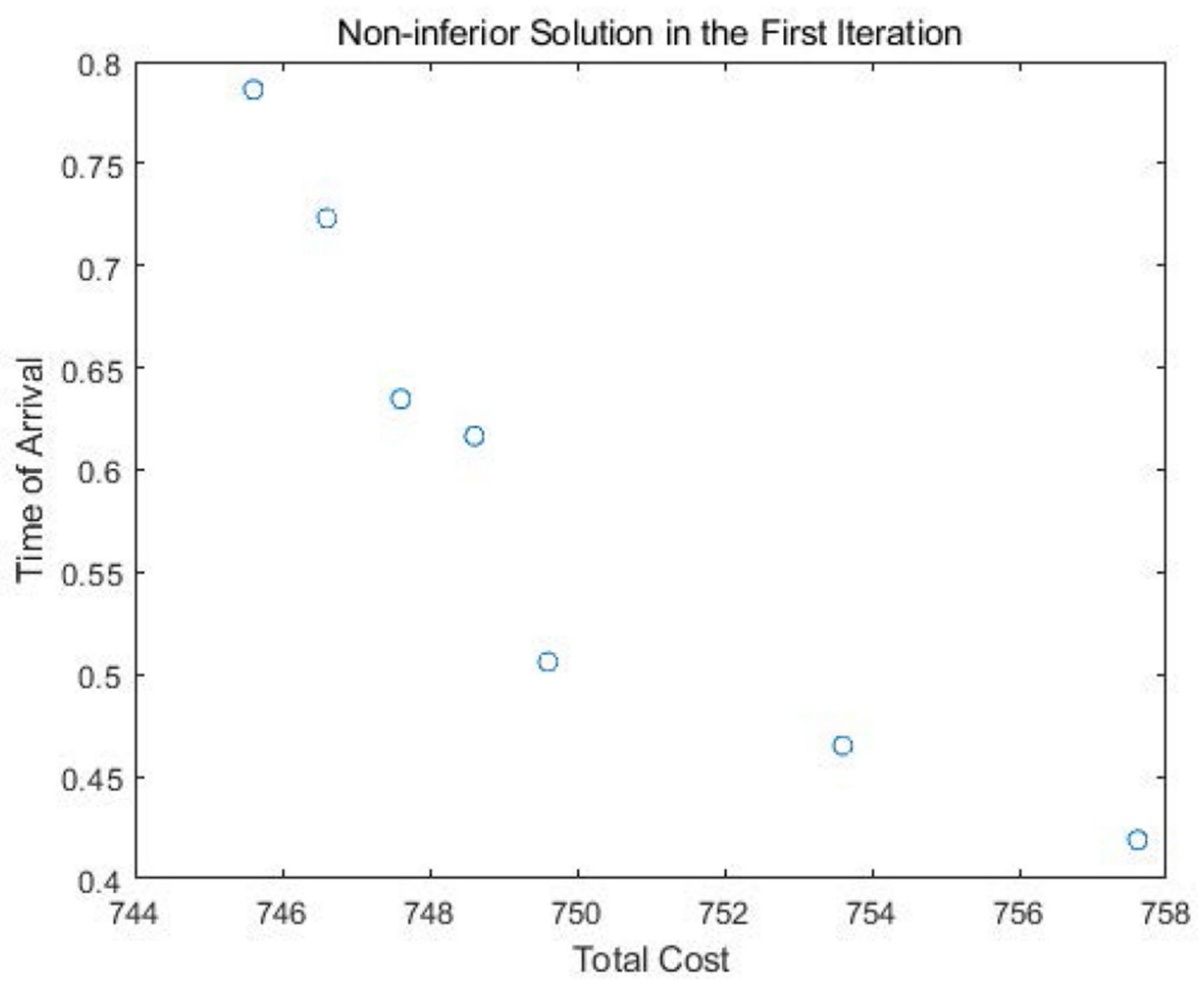

Fig. 8 Non-inferior Solution in the First Iteration Map

Step 3 Using the same method, a pairwise comparison matrix $\mathrm{B}$ of the economic factors at the scheme level to the criterion level is obtained as follows.

$$
B_{1}=\left[\begin{array}{lllllll}
1 & \frac{1}{4} & \frac{1}{3} & \frac{1}{2} & 2 & 4 & 6 \\
4 & 1 & 2 & 3 & 4 & 6 & 8 \\
3 & \frac{1}{2} & 1 & 3 & 5 & 6 & 8 \\
2 & \frac{1}{3} & \frac{1}{3} & 1 & 2 & 4 & 6 \\
\frac{1}{2} & \frac{1}{4} & \frac{1}{5} & \frac{1}{2} & 1 & 3 & 5 \\
\frac{1}{4} & \frac{1}{6} & \frac{1}{6} & \frac{1}{4} & \frac{1}{3} & 1 & 3 \\
\frac{1}{6} & \frac{1}{6} & \frac{1}{3} & \frac{1}{3} & \frac{1}{5} & \frac{1}{3} & 1
\end{array}\right] \text {,from the forum (8), relative com- }
$$

ponents of eigenvectors are obtained.

$\omega_{1}^{(3)}=\left[\begin{array}{lllllll}0.113 & 0.332 & 0.267 & 0.139 & 0.082 & 0.043 & 0.024\end{array}\right]^{T}$, from formula (9) and (10) for carrying out consistency test, $C I=0.063<0.1$ and $C R=0.047<0.1$ are obtained, the inspection is passed.
In a similar way, we can obtain:

$\omega_{2}^{(3)}=\left[\begin{array}{lllllll}0.083 & 0.021 & 0.036 & 0.051 & 0.185 & 0.295 & 0.328\end{array}\right]^{T}$,

$C I=0.083<0.1, \quad C R=0.063<0.1 ;$

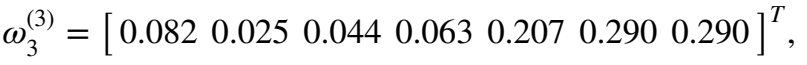

$C I=0.056<0.1, \quad C R=0.043<0.1 ;$

$\omega_{4}^{(3)}=\left[\begin{array}{lllllll}0.346 & 0.095 & 0.191 & 0.051 & 0.023 & 0.095 & 0.200\end{array}\right]^{T}$,

$C I=0.056<0.1, \quad C R=0.042<0.1 ;$ All of them passed the consistency test.

From formula (11), the combination weight vector of the scheme layer to the target layer is obtained as follows: 


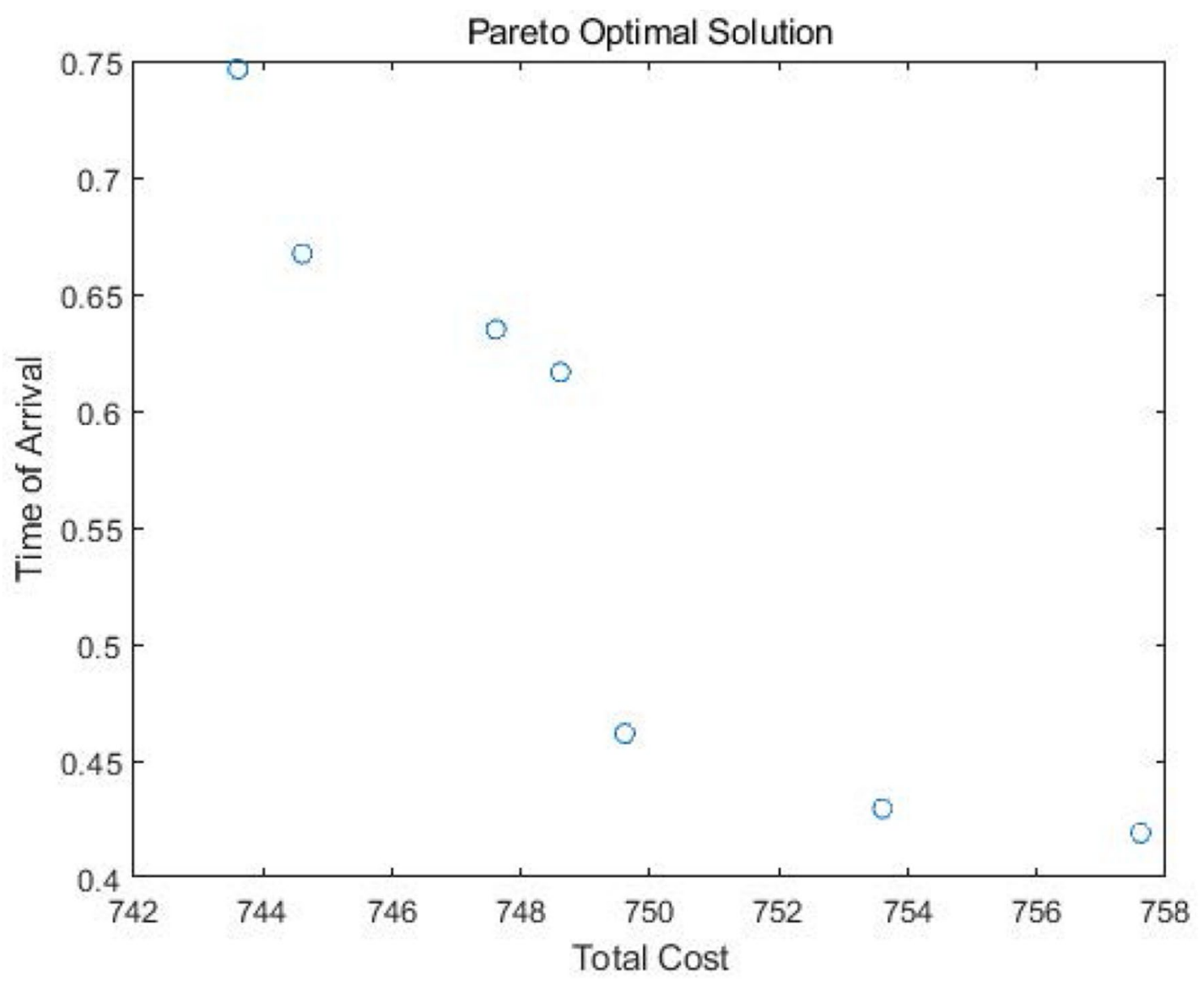

Fig. 9 Pareto Optimal Solution Set Distribution Graph

Table 6 Site selection modes and objective function values corresponding to each site selection

\begin{tabular}{llllllll}
\hline & Scheme one & Scheme two & Scheme three & Scheme four & Scheme five & Scheme six & Scheme seven \\
\hline $\begin{array}{l}\text { Site } \\
\text { selection }\end{array}$ & $2,6,9$ & $1,8,9$ & $1,6,9$ & $1,6,10$ & $1,4,10$ & $1,4,7$ & $2,4,7$ \\
Coverage & $2 \rightarrow 1,2,3$ & $1 \rightarrow 1,2,3$ & $1 \rightarrow 1,2$ & $1 \rightarrow 1,2$ & $1 \rightarrow 1,2$ & $1 \rightarrow 1,2$ & $2 \rightarrow 1,2$ \\
& $6 \rightarrow 4,5,6$ & $8 \rightarrow 5,7,8,10$ & $6 \rightarrow 3,4,5,6$ & $6 \rightarrow 3,4,5,6,9$ & $4 \rightarrow 3,4,5,6$ & $4 \rightarrow 3,4,5,6$ & $4 \rightarrow 3,4,5,6$ \\
& $9 \rightarrow 7,8,9,10$ & $9 \rightarrow 4,6,9$ & $9 \rightarrow 7,8,9,10$ & $10 \rightarrow 7,8,10$ & $10 \rightarrow 7,8,9,10$ & $7 \rightarrow 7,8,9,10$ & $7 \rightarrow 7,8,9,10$ \\
Total cost & 748 & 743 & 744 & 747 & 749 & 753 & 757 \\
Time of arrival (h) & 0.61 & 0.74 & 0.66 & 0.63 & 0.46 & 0.42 & 0.41 \\
\hline
\end{tabular}

(Note: The unit of total cost is 10,000 yuan) 


$$
\begin{aligned}
& \omega=\left[\begin{array}{llll}
\omega_{1}^{(3)} & \omega_{2}^{(3)} & \omega_{3}^{(3)} & \omega_{4}^{(3)}
\end{array}\right] \times W^{(2)}
\end{aligned}
$$

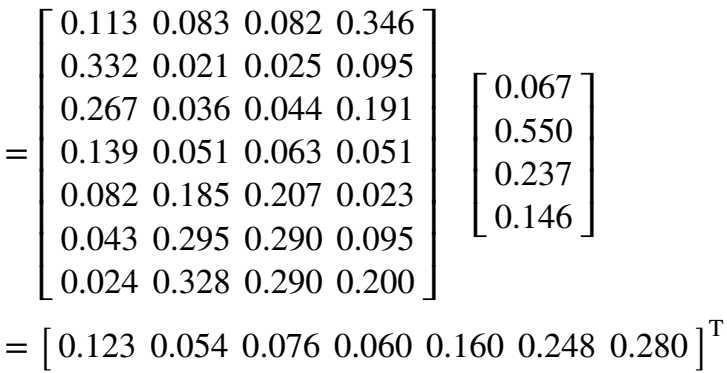

Among, weight vector of $W^{(2)}$ criterion layer elements to target layer, $\omega_{1}^{(3)}, \omega_{2}^{(3)}, \omega_{3}^{(3)}, \omega_{4}^{(3)}$ is the weight vector of each element of the scheme layer to the criterion layer.

$C R^{*}=\left[\begin{array}{llll}0.047 & 0.063 & 0.043 & 0.042\end{array}\right]\left[\begin{array}{l}0.067 \\ 0.550 \\ 0.237 \\ 0.146\end{array}\right]=0.054<0.1$

Therefore, combination consistency test is passed.

According to the above calculation results, the combined weight vectors of each site selection scheme in the target are obtained as follows:

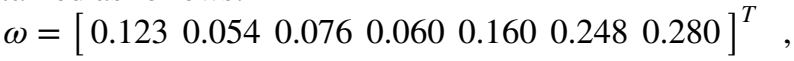

The results show that the comprehensive evaluation of seven site selection schemes from high to low is: scheme 7 , scheme 6 , scheme 5 , scheme 1 , scheme 3 , scheme 4 and scheme 2. According to the results of comprehensive evaluation, scheme 7 shall be selected.

\section{Research conclusion}

In this paper, an optimization model for site selection of fire safety points in mega project sites is proposed and verified by an example of a mega project in Sichuan Province. It has certain theoretical and practical significance. However, there are still some problems to be further studied.

- The coverage of fire safety points only involves the primary risk sources which are extremely vulnerable to fire safety accidents, there are some limitations in considering other demand points which are not easy to occur fire safety accidents in the construction site, which can only reduce the losses caused by fire safety accidents to a certain extent. Therefore, taking the coverage of fire safety points into accounting the demand points of the whole construction site needs further study.

- In the article site selection model, only four representative factors are considered to participate in site selection selection, but it is not comprehensive enough; Secondly, the model assumes that there are no other fire safety points in the site, however, in the actual layout, fire safety points will be considered in the site. Therefore, with the deepening of the research, how to make the theoretical model closer to the actual site selection optimization problem has become the focus of researchers.

- The improvement of particle swarm optimization still has great research potential. The reasonable setting of parameters is studied. On the one hand, it promotes the development of algorithm, on the other hand, it can serve multi-objective optimization problems better. At the same time, the problem is simplified in the construction of set selection optimization model. There are some shortcomings in solving practical engineering projects. In the future research, the content of the model shall be further enriched to make the model closer to the actual situation of the project.

Open Access This article is licensed under a Creative Commons Attribution 4.0 International License, which permits use, sharing, adaptation, distribution and reproduction in any medium or format, as long as you give appropriate credit to the original author(s) and the source, provide a link to the Creative Commons licence, and indicate if changes were made. The images or other third party material in this article are included in the article's Creative Commons licence, unless indicated otherwise in a credit line to the material. If material is not included in the article's Creative Commons licence and your intended use is not permitted by statutory regulation or exceeds the permitted use, you will need to obtain permission directly from the copyright holder. To view a copy of this licence, visit http://creativecommons.org/licenses/by/4.0/.

\section{References}

1. Hong R (2004) Major project management change - the proposal of giant project management [C]/Chinese Academy of Engineering. Engineering Management, Hong Kong Annual Meeting

2. Wei Z, Hong R et al (2011) Research on cooperation and coordination of giant project organization alliance based on cooperative game[J]. China Civ Eng J 01:215-219

3. Wu J et al (2016a) Big data meet green challenges: Big data toward green applications. IEEE Syst J 10(3):888-900

4. Wu J et al (2016b) Big data meet green challenges: greening big data. IEEE Syst J 10(3):873-887

5. Atat R et al (2018) Big data meet cyber-physical systems: A panoramic survey. IEEE Access 6:73603-73636

6. Wu J, Guo S, Huang H et al (2018) Information and communications technologies for sustainable development goals: state-ofthe-art, needs and perspectives[J]. IEEE Commun Surv Tutor 20(3):2389-2406

7. Zhuo J, Lu H (2017) Study on multi-objective optimization of engineering project based on particle swarm optimization algorithm [J]. J Eng Manag 31(06):101-106

8. Badri MA, Mortagy AK, Alsayed CA (1998) Amulti-objective model for locating fire stations. Eur J Oper Res 110:243-260 
9. Murray AT, Wei R (2013) A computational approach for eliminating error in the solution of the location set covering problem [J]. Eur J Oper Res 224(1):52-64

10. Araz C, Swlim H, Ozkarahan I (2007) A fuzzy multi-objective covering-based vehicle location model for emergency services. Comput Oper Res 34:705-726

11. Tzeng GH, Chen YW (1999) The optimal location of airport fire stations: a fuzzy multi-objective programming and revised genetic algorithm approach [J]. Trans Plan Technol 23(1):37-55

12. Cath R, Jim P (2000) Systems Options Ltd, Fire Cover Modeling for Brigades-Summary Report

13. Badri MA et al (1998) A multi-objective model for locating fire stations. Eur J Oper Res 110:243-260

14. Kanoun I, Habib C et al (2010) Goal programming model for fire and emergency service facilities site selection [J]. INFOR 48(3):143-153

15. Xu Z, Gong X (2007) Study on location selection of urban fire station based on multi-objective fuzzy optimization theory[J]. China Publ Secur Sci Edit 01:59-61

16. Wei L, Li H-L, Liu Q et al (2011) Study and implementation of fire sites planning based on GIS and AHP. Proc Eng 11:486-495

17. Yuanxue Z (2007) Research on fire prevention planning of major hazard sources based on multi-objective fuzzy theory[D]. Tianjin University, Tianjin

18. Wu L (2003) Theoretical model for determination of area of fire station responsibility area [A]. China fire protection association. In: 2003 proceedings of international conference on fire science and fire engineering $[\mathrm{C}], \mathrm{p} 4$

19. Chen C, Ren A (2003) Computer method for layout optimization of fire stations [J]. J Tsinghua Univ Sci Technol, 43(10)

20. Liu N, Huang B, Chandramouli M (2006) Optimal siting of fire stations using GIS and ANT algorithm [J]. J Comput Civ Eng 20(5):361-369

21. Yang L, Jones BF, Yang SH (2007) A fuzzy multi-objective programming for optimization of fire station locations through genetic algorithms [J]. Eur J Oper Res 181(2):903-915

22. Wei W, Li H, Liu Q et al (2010) Fire station planning based on GIS and AHP[J]. Fire Sci Technol 29(9):827-831
23. GB 50720-2011, Fire safety technical specification for construction site construction site[S]

24. GB/T 50502-2009, Architectural construction organization design specification[S]

25. Li Y, Guo Y, Sima Y (2019) State evaluation and control of dangerous sources of high-rise buildings based on improved LEC evaluation method[J]. J China Three Gorges Univ Nat Sci 41(04):55-59

26. Zhang M (2018) Study on multi-objective location model of chemical park fire station based on potential life loss value[D]. Tianjin University of Technology

27. Zhang W (2018) Multi-objective optimization of substation engineering projects based on particle swarm optimization[D]. North China Electric Power University

28. Lu Z (2017) Method and application of site selection for land consolidation project based on multi-objective particle swarm optimization algorithm [D]. Gansu Agricultural University

29. Riccardo P, Andries E, Jim K (2009) Editorial for the special issue on particle swarm optimization [J]. Swarm Intelligence, 3(4)

30. Sheng L (2014) Substation location method and application based on fuzzy grey correlation projection [D]. North China Electric Power University, Beijing

31. Li Z, Nie F, Chang X, Yang Y (2017) Beyond trace ratio: weighted harmonic meanof trace ratios for multiclass discriminant analysis. IEEE Trans Knowl Data Eng 10(1):2100-2110

32. Wang B, Xie H, Ren H, Li W (2019) Evaluation of remediation of petroleum contaminated soil based on analytic hierarchy process[J]. J Saf Environ 19(03):985-991

33. Liang Y (2019) Application of AHP analytic hierarchy process in the use of safety and civilization construction cost of transmission and distribution engineering $[\mathrm{J}]$. Telecom Power Technol 36(07):203-206

Publisher's Note Springer Nature remains neutral with regard to jurisdictional claims in published maps and institutional affiliations. 